\title{
Nonsurgical periodontal treatment and prosthetic rehabilitation of a renal transplant patient with gingival enlargement: a case report with 2-year follow-up
}

\author{
Chi-Ching Chang ${ }^{1 *}\left(\mathbb{D}\right.$, Tai-Min Lin $^{2}$, Chiu-Po Chan ${ }^{1}$ and Whei-Lin Pan ${ }^{1}$
}

\begin{abstract}
Background: Drug-induced gingival enlargement is a common condition which can be observed in patients taking immunosuppressive medications following organ transplant surgery. The disfiguring excessive tissue often hinders proper oral hygiene practices, therefore accompanied by periodontitis, tooth mobility, and even pathological tooth migration in extreme cases. This case report presents a conservative treatment protocol for a patient with the aforementioned conditions involving neither surgical nor orthodontic intervention. Few related studies have reported such a noninvasive protocol for managing these kinds of conditions.

Case presentation: A 51-year-old woman presented with bleeding gingiva, mobile teeth and complained of chewing difficulties. She had undergone renal transplant surgery 16 years prior to this dental visit and had been taking immunosuppressive drugs including cyclosporine ever since. After clinical and radiographic examinations, the patient was diagnosed with drug-induced gingival enlargement, pathological tooth migration, severe periodontitis, and missing teeth. Through careful and meticulous nonsurgical debridement, oral hygiene instruction, tooth extraction, and occlusal adjustment, the patient's periodontium was restored to a healthy state without surgical intervention. Moreover, the patient's chewing function was restored by means of removable partial dentures. Good adaptation of prostheses and satisfaction with overall treatment outcomes were reported.

Conclusions: Through proper diagnosis, treatment, and with good patient cooperation, complex systemic and dental problems can be managed conservatively without invasive surgeries to attain a stable periodontium and eventually, occlusal function could be restored.
\end{abstract}

Keywords: Nonsurgical treatment, Gingival enlargement, Cyclosporine, Pathological tooth migration

\section{Background}

The kidneys are vital organs responsible for multiple functions in the human body including metabolic waste excretion, water and electrolyte balance, hormone production, and body fluid osmolality regulation. In cases of conditions such as diabetes and hypertension or under the influence of various drugs, the kidneys might

\footnotetext{
* Correspondence: garych.gg@gmail.com

'Department of Periodontics, Taipei Chang Gung Memorial Hospital, Graduate Institute of Dental and Craniofacial Science, Chang Gung University, 6F., No.199, Dunhua N. Rd., Songshan Dist., Taipei City 105, Taiwan Full list of author information is available at the end of the article
}

gradually lose their function, which can subsequently result in chronic kidney disease (CKD). As CKD progress to stage 5 , which is also called end-stage renal disease (ESRD) or kidney failure, dialysis or transplantation would be inevitable [1].

Renal transplantation is a reliable treatment option for patients with ESRD, but these patients would have to take immunosuppressive drugs throughout their lives. Cyclosporine is a widely used immunosuppressive agent, and gingival enlargement is a well-documented side effect of this drug [2,3]. Gingival enlargement refers to

(c) The Author(s). 2018 Open Access This article is distributed under the terms of the Creative Commons Attribution 4.0 International License (http://creativecommons.org/licenses/by/4.0/), which permits unrestricted use, distribution, and reproduction in any medium, provided you give appropriate credit to the original author(s) and the source, provide a link to the Creative Commons license, and indicate if changes were made. The Creative Commons Public Domain Dedication waiver (http://creativecommons.org/publicdomain/zero/1.0/) applies to the data made available in this article, unless otherwise stated. 
fibrotic and sometimes lobulated growth disfigurement in the oral soft tissue, usually found at the anterior facial interdental papillae. The prevalence of gingival enlargement with respect to the immunosuppressive drug cyclosporine is $25-30 \%$ in adults and over $70 \%$ in children [4]. Patients with gingival enlargement often hinders proper oral hygiene practice [5] and may induce periodontal diseases. Based on the increasing number of transplantations being performed [6], this condition is increasingly seen in dental offices; treating such patients is often challenging [7].

Pathological tooth migration is a common complication of periodontal disease [8] that is defined as the deviation of tooth position due to force, inflammation, or both. The prevalence of pathological tooth migration ranges from 30.3 to $55.8 \%$. Common etiologies include periodontal tissue destruction, occlusal forces, soft tissue pressure, oral habits, and gingival enlargement [8-11]. Esthetics and proper occlusal function are compromised by pathological tooth migration. Treatment should begin with diagnosis to identify the etiological factors (e.g., tissue inflammation, loss of support, occlusal interferences); eliminating these factors could results in complete or partial resolution of the malalignment [12].

The case presented in this paper details the treatment process of an immunosuppressed renal transplant receiver with complex conditions including severe periodontitis, gingival enlargement, and pathological tooth migration.

\section{Case presentation}

A 51-year-old woman presented with chief complaints of bleeding gums and chewing disability. Her medical history revealed that she had received renal transplantation surgery in 1999 and had remained in a stable condition without graft-versus-host disease ever since. She suffered from hypertension and gout, both of which were being well controlled and followed by treating physicians. Her medications at the time of initial examination including the immunosuppressive regimen (cyclosporine, prednisolone, and mycophenolate mofetil) are listed in Table 1. The patient was a nonsmoker who did not consume alcohol. She stated that she seldom brushed her teeth and had not flossed for a long time because of serious gum bleeding upon brushing or flossing.

A facial examination revealed normal appearance without lymph node enlargement or local heat. No temporomandibular joint related symptoms were reported. Normal hard and soft tissue were observed in the patient's oropharynx, hard and soft palates, floor of the mouth and tongue. An intraoral examination revealed highly inflamed periodontal tissue with heavy plaque and calculus deposition. Fibrotic changes over interdental
Table 1 Medications at initial examination

\begin{tabular}{lll}
\hline Medication & Usage (Class) & Dosage \\
\hline Cyclosporine & $\begin{array}{l}\text { Immunosuppressive } \\
\text { (Calcineurin inhibitor) }\end{array}$ & $50 \mathrm{mg} / \mathrm{BID}$ \\
Prednisolone & $\begin{array}{l}\text { Immunosuppressive } \\
\text { (Corticosteroid) }\end{array}$ & $5 \mathrm{mg} / \mathrm{QD}$ \\
Mycophenolate mofetil & $\begin{array}{l}\text { Immunosuppressive } \\
\text { (Anti-proliferative) }\end{array}$ & $250 \mathrm{mg} / \mathrm{BID}$ \\
Atenolol & $\begin{array}{l}\text { Blood pressure control } \\
\text { (B-blocker) }\end{array}$ & $100 \mathrm{mg} / \mathrm{QD}$ \\
Benzbromarone & $\begin{array}{l}\text { Gout treatment } \\
\text { (Uricosuric agent) }\end{array}$ & $50 \mathrm{mg} / \mathrm{QOD}$ \\
Colchicine & $\begin{array}{l}\text { Gout treatment } \\
\text { (Anti-inflammatory) }\end{array}$ & $0.5 \mathrm{mg} / \mathrm{QOD}$ \\
\hline
\end{tabular}

papillae, facial and also lingual gingivae were noted, especially in the anterior segment (Fig. 1). The patient's upper left and lower left molars were missing. Her anterior teeth were flaring and highly mobile with a diastema of approximately $2.5 \mathrm{~mm}$ between the maxillary central incisors. Upon examination, we noted full mouth deep probing pocket depth (up to $15 \mathrm{~mm}$ ) and profound bleeding. A fistula with suppuration was observed over buccal gingiva of tooth 46 (lower right first molar). Periapical films revealed generalized horizontal bone loss with the supporting bone of less than one half or one third of the root length. Periradicular radiolucency with an angular bony defect extending beyond the apex was observed over the mesial root of tooth 46 (Fig. 2).

The clinical diagnosis was severe periodontitis and gingival disease modified by medication [13]. A hopeless prognosis was assigned to tooth 46. After consultation with treating physicians and discussion with the patient, a tentative treatment plan was formed involving cause-related periodontal treatment and extraction of tooth 46 . In addition, the immunosuppressive regiment was not altered.

The patient was treated in the Department of Periodontics in Taipei Chang Gung Memorial Hospital between July 2014 and January 2015. Dental appointments were coordinated with physician appointments to obtain blood test results before each dental visit. Data were mostly within the normal range except for the occurrence of mild thrombocytopenia (listed in Table 2). Prophylactic antibiotics (amoxicillin, $2 \mathrm{~g}$ ) were prescribed before each appointment [14]. The treatments included scaling, root planing, oral hygiene instruction, and extraction. Although tooth mobility decreased after multiple visits, we discovered occlusal interference during the patient's lateral excursion and anterior jaw movement; therefore, occlusal adjustment was incorporated into the treatment plan. Six months after the patient's initial visit, a marked improvement of her periodontal condition as well as more effective plaque control were 

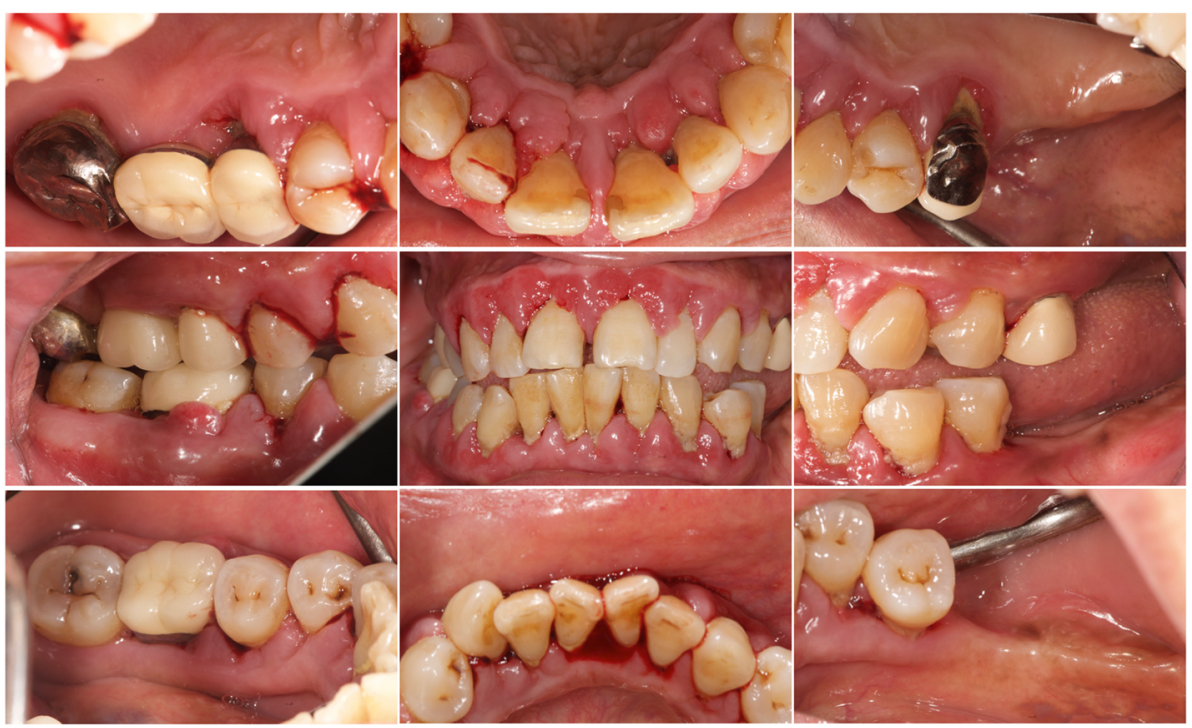

Fig. 1 Initial clinical views. Inflammatory and fibrotic gingivae with spontaneous bleeding tendency. Note a 2.5-mm diastema between the upper central incisors, fistula over the lower right first molar, and malocclusion over the left premolars due to hypermobility

observed. The gingivae were considerably less edematous and glazed and without any residual fibrotic appearance (Fig. 3). The periodontal probing result revealed some residual but largely decreased periodontal pockets and grade I tooth mobility over the upper and lower anterior teeth and lower right second molar [15]. In addition, the diastema between the upper incisors closed "spontaneously" after treatment.

Pocket elimination periodontal surgery was initially planned to treat the upper right and lower right second molars; however, nonsurgical treatment was eventually selected as the final treatment plan after the patient rejected surgery and the residual periodontal pocket depth were mostly less than $6 \mathrm{~mm}$ with horizontal bone loss pattern (Fig. 4) [16]. After 3 months of follow-up, the patient was referred to our prosthodontic department for oral rehabilitation with removable partial dentures. The dentures were designed with palatal strap, lingual bar, and wrought-wire clasps (Fig. 5). The periodontal supportive treatment recall interval was monthly in the first year and every 3 months subsequently [17]. A clinical examination and periodontal probing after 2 years of follow-up revealed excellent oral hygiene, continuous pocket reduction, and tooth mobility within normal limit for all remaining teeth (Figs. 4 and 6). The difference of attachment level gain, probing depth
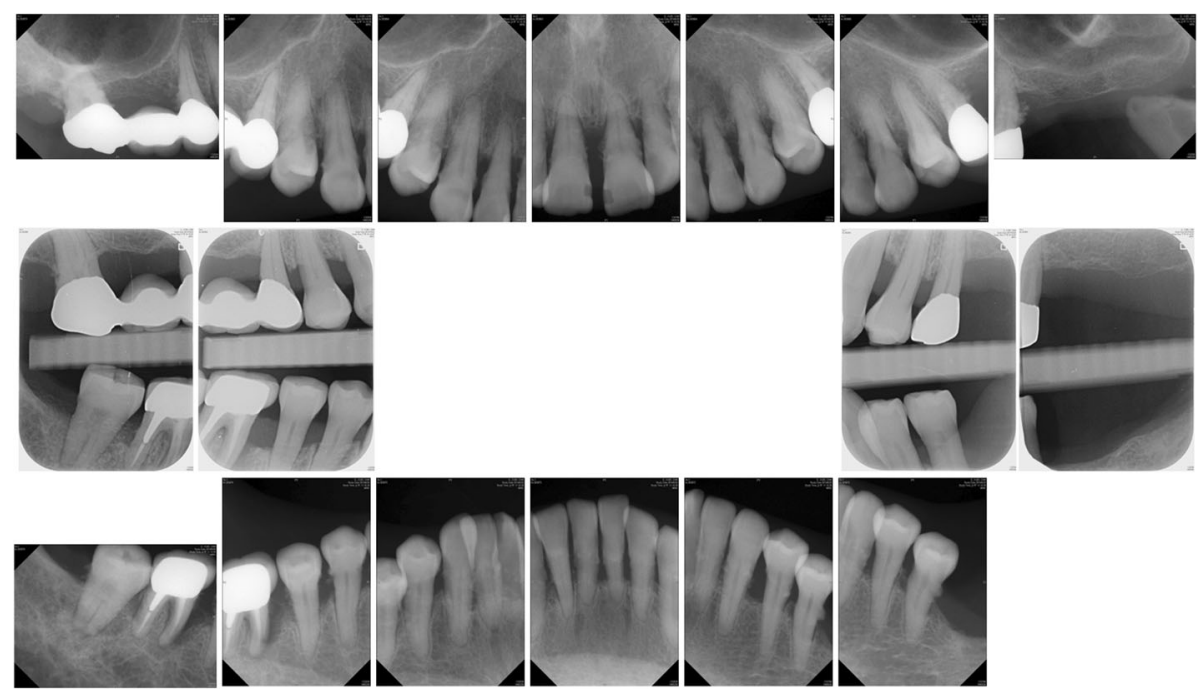

Fig. 2 Initial radiographs. Note the bone loss over mesial root of the lower right first molar and multiple subgingival deposits 
Table 2 Blood test results prior to each appointment

\begin{tabular}{|c|c|c|c|c|c|c|c|}
\hline Test/visit & Treament1 & Treament2 & Treament3 & Treatment4 & Treatmen5 & Treatment6 & Extraction \\
\hline eGFR (mL/min/1.73) & 44 & 40 & 41 & 41 & 41 & 33 & 44 \\
\hline Creatinine $(\mathrm{mg} / \mathrm{dL})$ & 1.29 & 1.39 & 1.36 & 1.35 & 1.37 & 1.64 (high) & 1.27 \\
\hline $\operatorname{RBC}\left(10^{6} / \mathrm{uL}\right)$ & 3.84 & 3.81 & 3.72 & 3.78 & 3.77 & 3.72 & 3.7 \\
\hline Hemoglobin (g/dL) & 12.4 & 12.1 & 11.9 (low) & 12 & 12.2 & 11.8 (low) & 11.7 (low) \\
\hline Hematocrit (\%) & 37.2 & 36.8 & 35.6 (low) & 36.7 & 36.6 & 36.5 & 36.2 \\
\hline WBC $\left(10^{3} / \mathrm{UL}\right)$ & 5.8 & 7.2 & 5.3 & 4.7 & 6.1 & 6.2 & 5 \\
\hline Platelet $\left(10^{3} / \mathrm{uL}\right)$ & 103 (low) & 87 (low) & 96 (low) & 101 (low) & 111 (low) & 102 (low) & 112 (low) \\
\hline
\end{tabular}

reduction, and change of the distance from cementoenamel junction to gingival margin (CEJ-GM) between anterior (canine to canine) and posterior teeth were shown in Fig. 7. No recurrence of gingival enlargement was recorded throughout the follow-up period. The diastema between the upper incisors remained closed without centric or lateral occlusal interference (Fig. 8). Full mouth periapical and bite-wing radiographs revealed that the alveolar bone level had been maintained from its initial condition (Fig. 9). The treating prosthodontist also recalled the patient regularly. The patient reported good chewing function, considerable ease in conducting oral hygiene practices, and overall high satisfaction with the treatment outcomes.

\section{Discussion and conclusions}

The main focus of nonsurgical periodontal treatment is to reduce tissue inflammation by eliminating bacterial biofilm, and the key to a successful outcome is the thoroughness of root debridement and patients' own plaque control ability [18]. According to previous studies, the overgrown tissue induced by cyclosporine tends to be more inflammatory and less fibrotic in nature than that induced by other agents $[19,20]$. By understanding these histological factors, we can reasonably assume that to some extent, such patients are less likely to require surgery. Nonsurgical periodontal therapy includes scaling, root planing, and oral hygiene reinforcement, were performed meticulously over multiple appointments in the case presented in this study; thus, the evident reduction in tissue enlargement was anticipated.

Although no precise dental treatment protocol for renal transplant patients has been established, the clinical approach should focus on eliminating infection sources and creating an oral environment that facilitates easy plaque control. Good communication between dentists and treating physicians is also very important. Practically, a treatment course should include oral hygiene instruction, use of antimicrobial mouthwash, scaling, root planing, and extraction if necessary. Antimicrobial

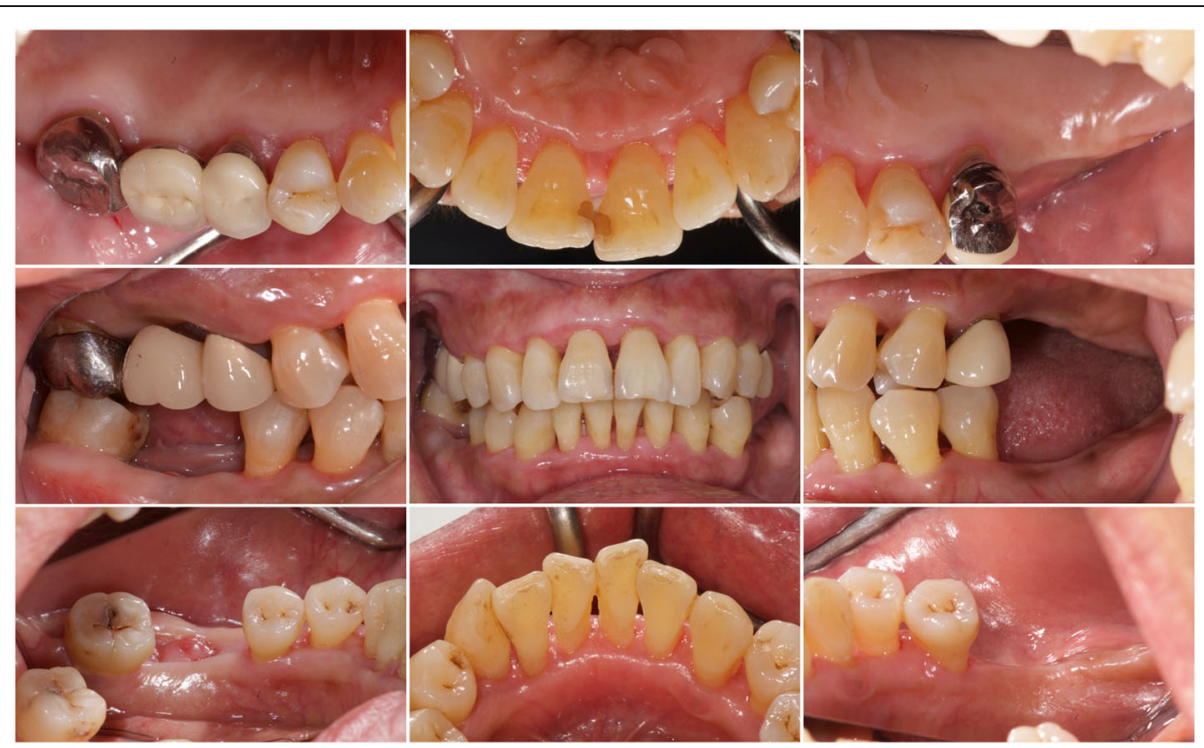

Fig. 3 Re-evaluation clinical views. The gingivae were less edematous and glazed. The diastema had closed. The extraction wound over the lower right first molar was in the process of healing. Occlusal contact had been regained over the left premolars 


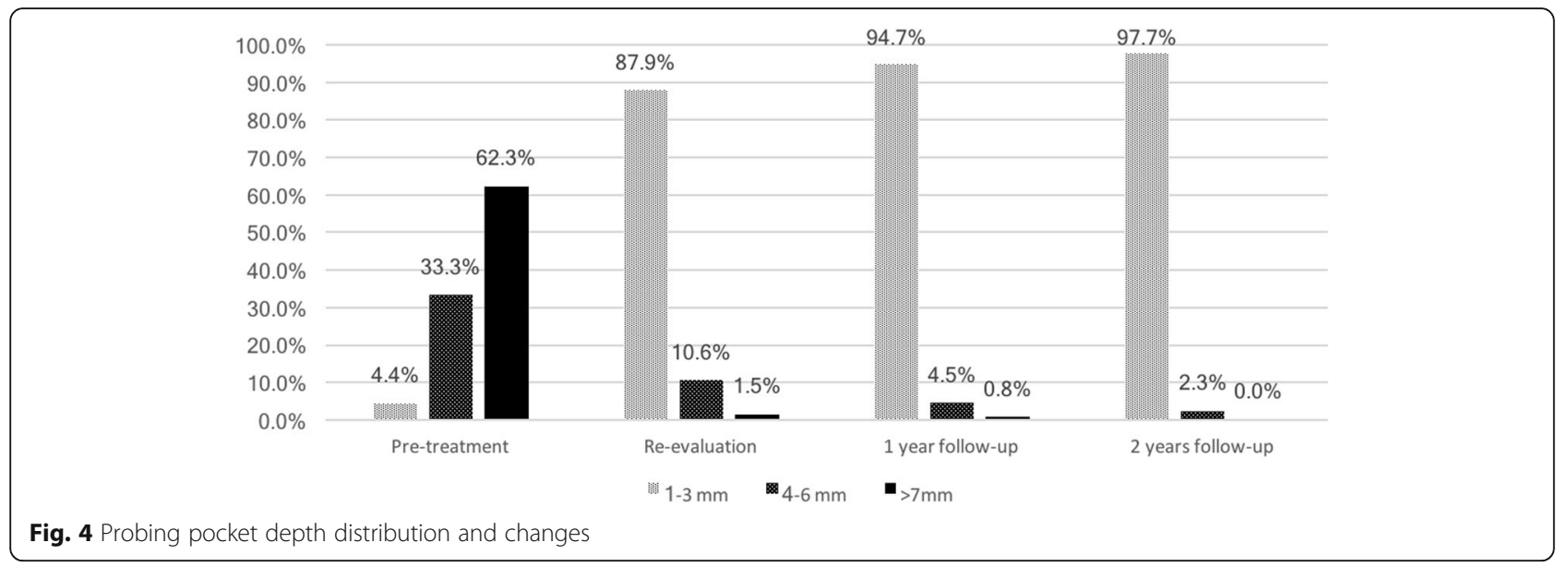

prophylaxis in accordance with the American Heart Association's regimen before invasive treatment was suggested; however, no evidence-based research supports the effect of it $[14,21]$. Clinicians should check patients' bleeding tendencies before invasive procedures, especially the platelet count $[22,23]$. Furthermore, specific medications, such as nonsteroidal anti-inflammatory drugs, macrolide antibiotics, and aspirin, should be avoided because they may interact with cyclosporine and raise the serum level of it due to patients' impaired renal function [24]. Long-term corticosteroid intake (as a supplementary immunosuppressive agent) may induce adrenal crises during pressure events such as prolonged and invasive dental treatment. Although avoidance of supplementary steroidal coverage was recommended in a double-blind study [25], patients should be administered with a stress-relieving protocol, and their blood pressure should be monitored during treatment [26].

Specific oral manifestations have been observed in renal transplant patients. In a descriptive study regarding clinical oral findings in patients who had undergone kidney transplants, the most prevalent finding was saburral tongue, followed by xerostomia, gingival enlargement, and oral candidiasis [27]. Various infectious lesions including bacterial, viral, and fungal lesions were observed in immunosuppressed patients [26]. Incidence of non-melanoma skin cancer was reported as 20 to 40 times higher in renal transplant receivers [28]. If such lesions are suspected, screening via culture or biopsy should be performed.

Although the detailed mechanism underlying cyclosporine-induced gingival enlargement is not fully known, interactions between the drug and genetically-determined susceptible gingival fibroblasts are widely believed to enhance protein synthesis, collagen production, and cell proliferation. In addition, elevated inflammatory cytokines (e.g., interleukin [IL]-6, IL-1 $\beta$ ) upregulate protein synthesis, which, combined with the decreased secretion of collagenase (e.g., matrix metalloproteinase [MMP]-1, MMP-3), results in tissue proliferation [4, 29]. Many risk factors for cyclosporine-induced gingival enlargement have been identified, including gender (male with higher risk), young age, high drug dosage, concomitant calcium channel blockers, impaired renal function [30], certain human leukocyte antigen phenotypes [31], and the presence of bacterial plaque [32].

For clinicians, the first approach to treat patients with immunosuppression and complex dental conditions should be consulting the treating physician in order to fully understand a patient's current systemic condition.
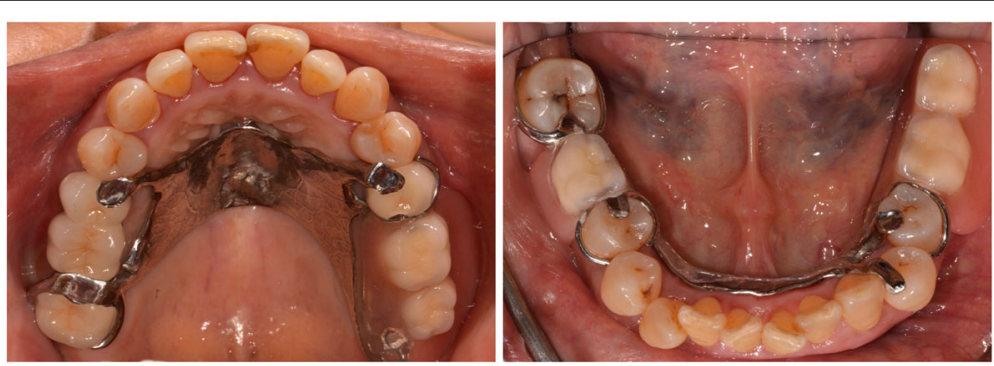

Fig. 5 Rehabilitation with removable partial dentures. The palatal strap and lingual bar with wrought-wire design favored periodontal compromised abutment teeth 


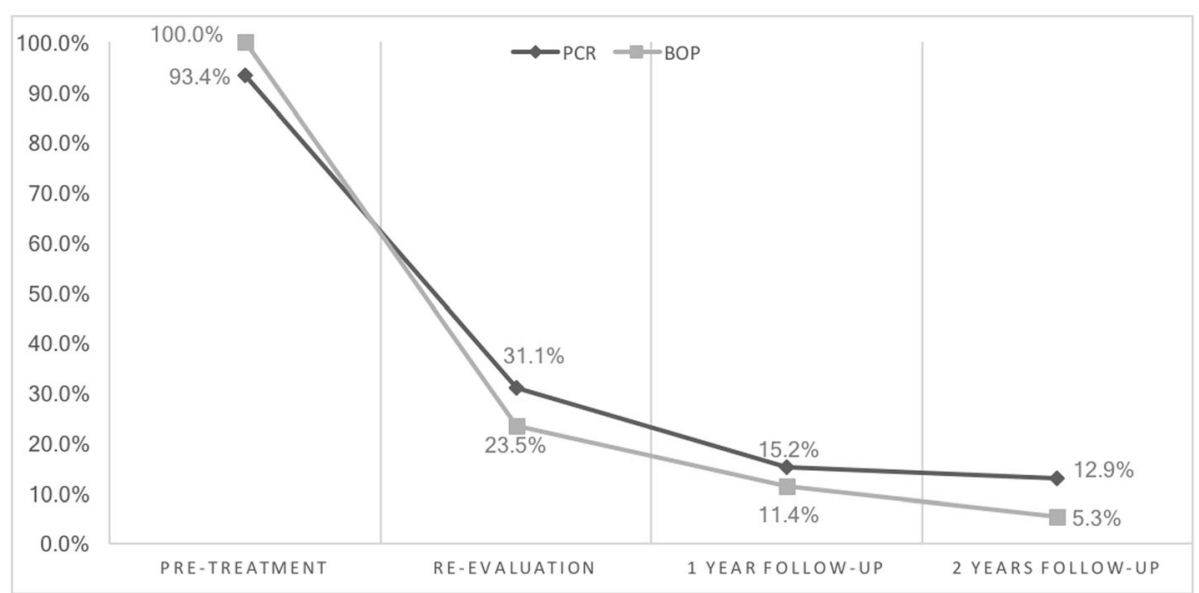

Fig. 6 Plaque control record (PCR) and bleeding on probing (BOP) distribution and changes

Subsequently, plaque-induced tissue inflammation should be eliminated by performing thorough cause-related therapy, and high-quality plaque control performance should be demanded of the patient. The literature contains many reports of resolving gingival enlargement or reducing the need for surgery through plaque control programs alone; most such articles have reported significant improvements in more than half of the patients in their study cohorts
$[33,34]$. Also, use of an adjunctive antiseptic mouthwash (chlorhexidine $0.1-0.2 \%$ ) might reduce the severity of enlargement and prevent its recurrence [35].

If tissue inflammation persists after meticulous nonsurgical debridement or the enlarged tissue is impairing a patient's periodontal health, self-performed cleaning ability, or esthetic appearance, surgical intervention is indicated. Many approaches for removing excessive
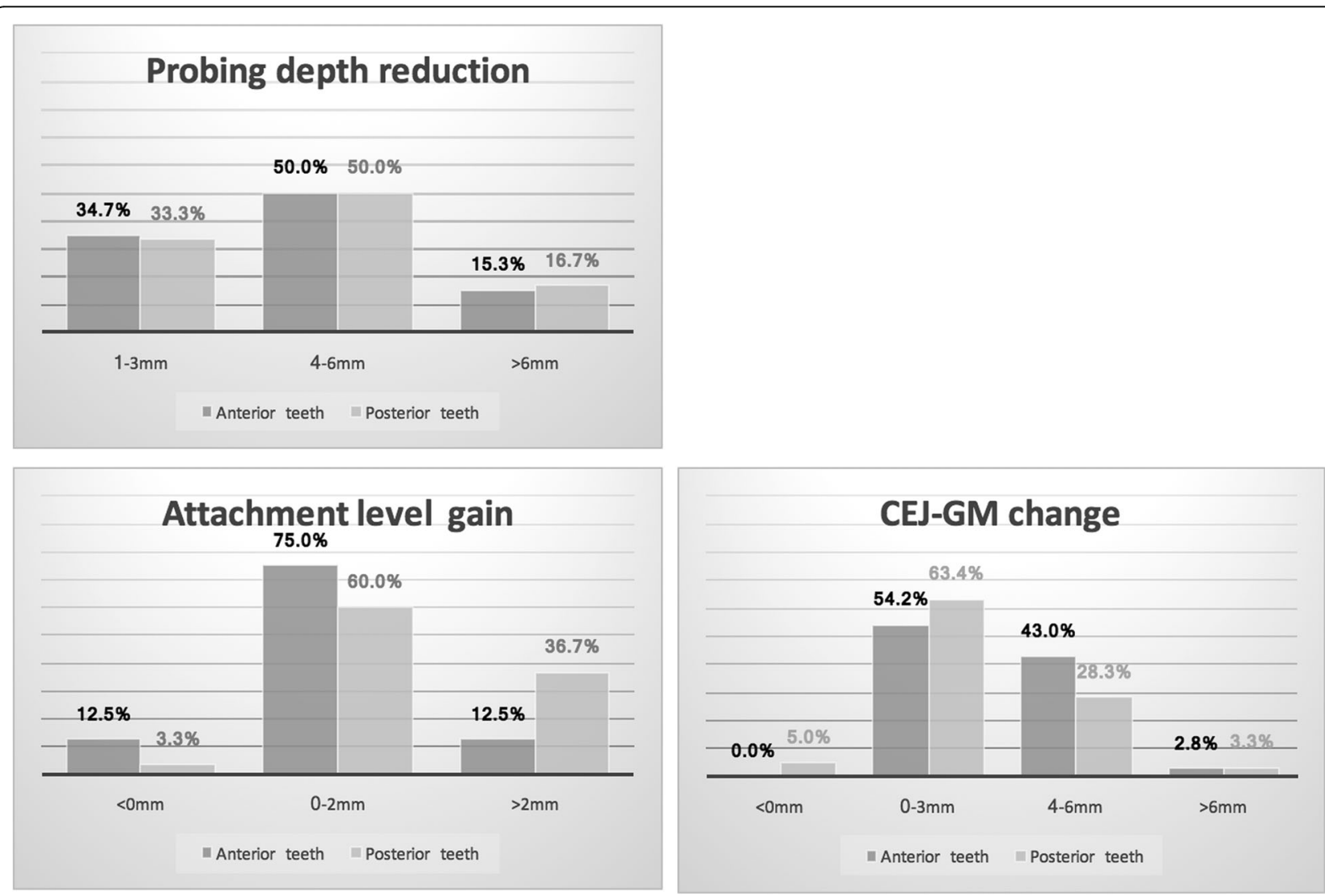

Fig. 7 Clinical probing data distribution and changes, comparison between anterior and posterior teeth 


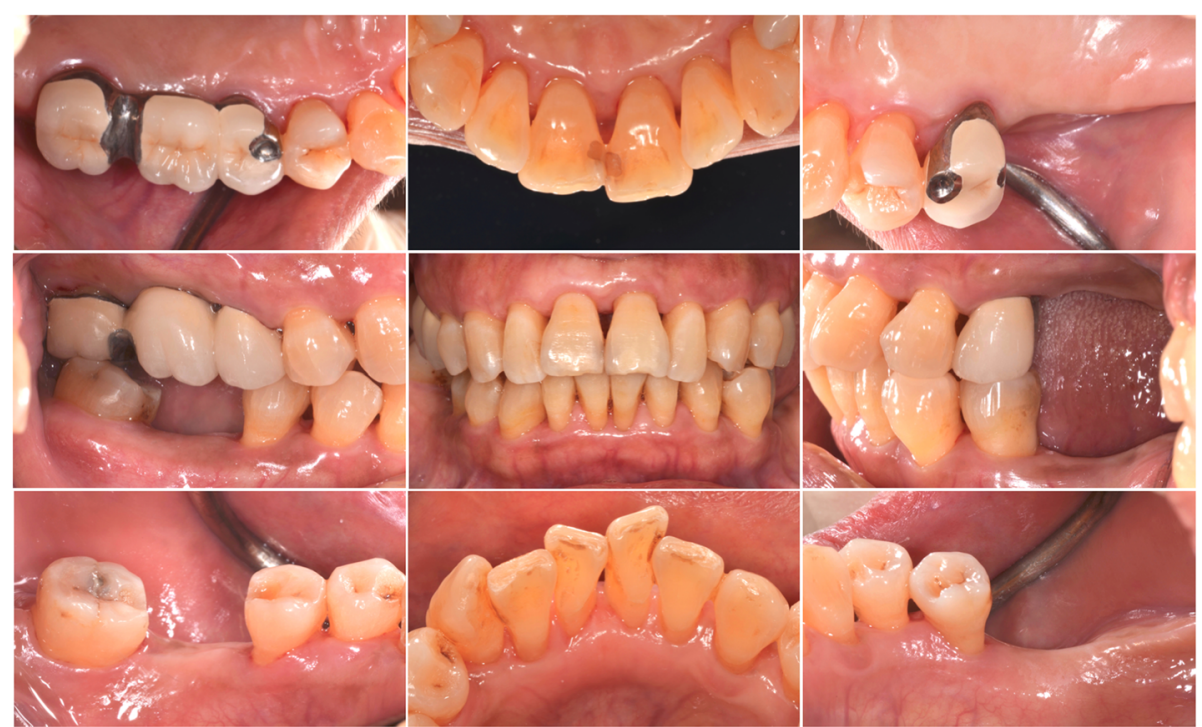

Fig. 8 Two-year follow-up clinical views. Stable tissue tonus and effective plaque control performed by the patient. The diastema had remained closed. A healed socket can be observed over the lower right first molar site

tissue are available, including scalpel gingivectomy, flap surgery, electrosurgery, and laser gingivectomy. In one study, the application of laser yielded a lower recurrence rate and higher patient satisfaction [36]. Switching a patient's immunosuppressive medication to tacrolimus could effectively resolve or in some cases completely reverse the gingival condition without surgical intervention [37, 38]. Consultation with a treating physician is required for drug alteration; however, such alterations are sometimes impossible because of medical or financial concerns [39].

By comparing the clinical data of anterior and posterior teeth from initial to 2-year follow up, it can be recognized, while the difference in probing depth reduction is minor, the attachment level gain was more pronounced in posterior segment, and the CEJ-GM level change ("gingival recession") was greater in the anterior teeth (Fig. 7). This is in accordance with the literature [4] and the initial clinical view of the current case report (Fig. 1), that the greatest amount of tissue enlargement was noted in the anterior segment. In the current case report, gingival enlargement gradually resolved throughout the course of a 6-month meticulous plaque control program without surgical intervention nor change in medication, and maintained in stable condition for more than 2 years (Figs. 4 and 6). Understanding the histology

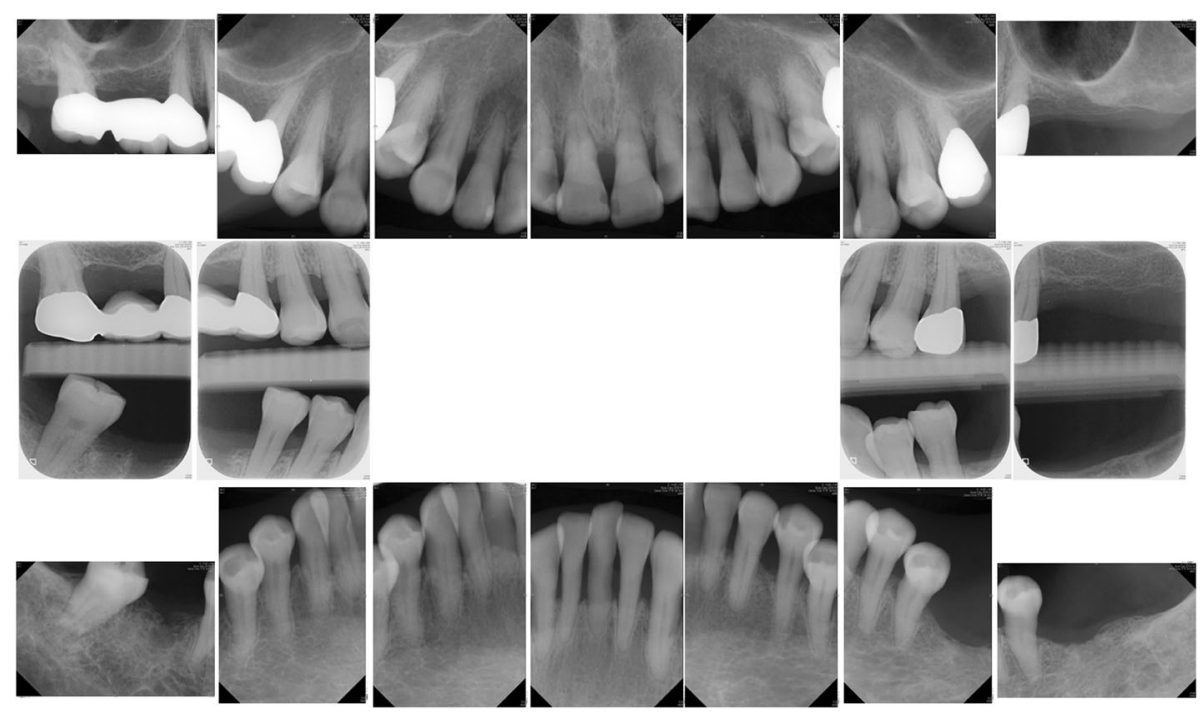

Fig. 9 Two-year follow-up radiographs. The bone level was maintained throughout the treatment course 
of the affected tissue [20], detailed diagnosis based on periodontal probing with radiographs depicting the bone loss pattern, and meticulous treatment and a short follow-up interval are keys to the success of conservative treatment approaches.

Periodontal treatment alone has the potential to "spontaneously" correct pathologically migrated tooth positioning [12, 40]; however, frequency and predictability are seldom mentioned in the literature. In a prospective clinical study that analyzed 33 periodontal patients with secondary diastemata, $36.4 \%$ and $51.5 \%$ of all tooth gaps were completely closed after nonsurgical periodontal treatment and surgical debridement, respectively. Moreover, the frequency was higher when the diastema was less than $1 \mathrm{~mm}$ [41]. In summary, according to the literature, elimination of periodontal tissue inflammation and minor occlusal adjustment should constitute the preliminary approach to treating pathologically migrated teeth. After inflammation and unfavorable forces have been controlled, orthodontic alignment or prosthodontic intervention can close the residual space and restore a patient's previous esthetic appearance.

In the patient investigated in the present study, the spacing between the upper anterior teeth closed and remained stable throughout the follow-up period after inflammation had been controlled and occlusal interferences had been eliminated. Prosthetic rehabilitation to regain posterior support facilitated long-term stability. No orthodontics were incorporated into the treatment process.

In conclusion, medically compromised patients with multiple dental problems remain a clinical challenge. Clinicians must fully understand patients' systemic conditions and consider every potential treatment option before making decisions. With proper diagnosis, treatment planning, and patient cooperation, complex conditions can be managed through simple approaches.

\section{Abbreviations}

CEJ-GM: CementoEnamel Junction to Gingival Margin; CKD: Chronic kidney disease; ESRD: End stage renal disease; IL: Interleukin; MMP: Matrix metalloproteinase

\section{Availability of data and materials}

All data generated or analyzed during this study are included in this published article.

\section{Authors' contributions}

CCC performed the initial examination, patient assessment, and periodontal treatment; reviewed the available literature; and drafted the manuscript. TML performed prosthodontic treatment. CPC and WLP reviewed the literature and corrected the drafted manuscript. All authors have read and approved the final manuscript.

\section{Ethics approval and consent to participate}

The protocol of this study was approved by the Institutional Review Board of Chang Gung Memorial Hospital (201800256B0). The treatment protocol was considered to be standard care without any experimental treatment approach or medications.

\section{Consent for publication}

Written informed consent was obtained from the patient for publication of this case report.

\section{Competing interests}

The authors declare that they have no competing interests.

\section{Publisher's Note}

Springer Nature remains neutral with regard to jurisdictional claims in published maps and institutional affiliations.

\section{Author details}

'Department of Periodontics, Taipei Chang Gung Memorial Hospital, Graduate Institute of Dental and Craniofacial Science, Chang Gung University, 6F., No.199, Dunhua N. Rd., Songshan Dist., Taipei City 105, Taiwan. ${ }^{2}$ Department of Prosthodontics, Taipei Chang Gung Memorial Hospital, Graduate Institute of Dental and Craniofacial Science, Chang Gung University, 6F., No.199, Dunhua N. Rd., Songshan Dist., Taipei City 105, Taiwan.

Received: 7 March 2018 Accepted: 8 August 2018

Published online: 20 August 2018

References

1. Levey AS, de Jong PE, Coresh J, El Nahas M, Astor BC, Matsushita K, et al. The definition, classification, and prognosis of chronic kidney disease: a KDIGO controversies conference report. Kidney Int. 2011;80:17-28.

2. Boltchi FE, Rees TD, lacopino AM. Cyclosporine A-induced gingival overgrowth: a comprehensive review. Quintessence Int. 1999;30:775-83.

3. Somacarrera ML, Hernandez G, Acero J, Moskow BS. Factors related to the incidence and severity of cyclosporin-induced gingival overgrowth in transplant patients. A longitudinal study. J Periodontol. 1994;65:671-5.

4. Dongari-Bagtzoglou A. Information paper: drug-associated gingival enlargement. J Periodontol. 2004;75:1424-31.

5. Camargo PM, Melnick PR, Pirih FQ, Lagos R, Takei HH. Treatment of druginduced gingival enlargement: aesthetic and functional considerations. Periodontol 2000. 2001;27:131-8.

6. Hart A, Smith JM, Skeans MA, Gustafson SK, Wilk AR, Robinson A, et al. OPTN/SRTR 2016 annual data report: kidney. Am J Transplant. 2018; 18(Suppl 1):18-113.

7. Georgakopoulou EA, Achtari MD, Afentoulide N. Dental management of patients before and after renal transplantation. Stomatologija. 2011;13:107-12.

8. Martinez-Canut P, Carrasquer A, Magan R, Lorca A. A study on factors associated with pathologic tooth migration. J Clin Periodontol. 1997;24:492-7.

9. Towfighi PP, Brunsvold MA, Storey AT, Arnold RM, Willman DE, McMahan CA. Pathologic migration of anterior teeth in patients with moderate to severe periodontitis. J Periodontol. 1997;68:967-72.

10. Brunsvold MA. Pathologic tooth migration. J Periodontol. 2005:76:859-66.

11. Fu E, Nieh S, Wikesjo UM, Lin FG, Shen EC. Gingival overgrowth and dental alveolar alterations: possible mechanisms of cyclosporin-induced tooth migration. An experimental study in the rat. J Periodontol. 1997;68:1231-6.

12. Brunsvold MA, Zammit KW, Dongari Al. Spontaneous correction of pathologic migration following periodontal therapy. Int J Periodontics Restorative Dent. 1997;17:182-9.

13. Armitage GC. Development of a classification system for periodontal diseases and conditions. Ann Periodontol. 1999;4:1-6.

14. Guggenheimer J, Mayher D, Eghtesad B. A survey of dental care protocols among US organ transplant centers. Clin Transpl. 2005;19:15-8.

15. Miller SC. Textbook of Periodontia: oral medicine. Philadelphia: Blakiston Co.; 1950. p. 91

16. Heitz-Mayfield LJ, Trombelli L, Heitz F, Needleman I, Moles D. A systematic review of the effect of surgical debridement vs non-surgical debridement for the treatment of chronic periodontitis. J Clin Periodontol. 2002;29(Suppl 3):92-102. discussion 60-2

17. Lang NP, Tonetti MS. Periodontal risk assessment (PRA) for patients in supportive periodontal therapy (SPT). Oral Health Prev Dent. 2003;1:7-16.

18. Cobb CM. Non-surgical pocket therapy: mechanical. Ann Periodontol. 1996; 1:443-90

19. Uzel Ml, Kantarci A, Hong HH, Uygur C, Sheff MC, Firatli E, et al. Connective tissue growth factor in drug-induced gingival overgrowth. J Periodontol. 2001;72:921-31. 
20. Trackman PC, Kantarci A. Molecular and clinical aspects of drug-induced gingival overgrowth. J Dent Res. 2015;94:540-6.

21. Nishimura RA, Otto CM, Bonow RO, Carabello BA, Erwin JP 3rd, Fleisher LA, et al. 2017 AHA/ACC focused update of the 2014 AHA/ACC guideline for the Management of Patients with Valvular Heart Disease: a report of the American College of Cardiology/American Heart Association task force on clinical practice guidelines. Circulation. 2017;135:e1159-e95.

22. Ferguson CA, Whyman RA. Dental management of people with renal disease and renal transplants. N Z Dent J. 1998;94:125-30.

23. Yang Y, Yu B, Chen Y. Blood disorders typically associated with renal transplantation. Front Cell Dev Biol. 2015;3:18.

24. Guggenheimer J, Eghtesad B, Stock DJ. Dental management of the (solid) organ transplant patient. Oral Surg Oral Med Oral Pathol Oral Radiol Endod. 2003;95:383-9

25. Thomason JM, Girdler NM, Kendall-Taylor P, Wastell H, Weddel A, Seymour RA. An investigation into the need for supplementary steroids in organ transplant patients undergoing gingival surgery. A double-blind, splitmouth, cross-over study. J Clin Periodontol. 1999;26:577-82.

26. Vasanthan A, Dallal N. Periodontal treatment considerations for cell transplant and organ transplant patients. Periodontol 2000. 2007:44:82-102.

27. Dirschnabel AJ, Martins Ade S, Dantas SA, Ribas Mde O, Gregio AM, Alanis $L R$, et al. Clinical oral findings in dialysis and kidney-transplant patients. Quintessence Int. 2011;42:127-33.

28. Khosravi M, Golchai J, Mokhtari G. Muco-cutaneous manifestations in 178 renal transplant recipients. Clin Transpl. 2011;25:395-400.

29. Seymour RA, Jacobs DJ. Cyclosporin and the gingival tissues. J Clin Periodontol. 1992;19:1-11.

30. Thomason JM, Seymour RA, Ellis JS. Risk factors for gingival overgrowth in patients medicated with ciclosporin in the absence of calcium channel blockers. J Clin Periodontol. 2005;32:273-9.

31. Thomason JM, Seymour RA, Ellis JS, Kelly PJ, Parry G, Dark J, et al. Determinants of gingival overgrowth severity in organ transplant patients. An examination of the role of HLA phenotype. J Clin Periodontol. 1996;23: 628-34

32. Fu E, Nieh S, Wikesjo UM. The effect of plaque retention on cyclosporineinduced gingival overgrowth in rats. J Periodontol. 1997;68:92-8.

33. Aimetti M, Romano F, Priotto P, Debernardi C. Non-surgical periodontal therapy of cyclosporin a gingival overgrowth in organ transplant patients. Clinical results at 12 months. Minerva Stomatol. 2005:54:311-9.

34. Castronovo G, Liani G, Fedon A, De ludicibus S, Decorti G, Costantinides F, et al. The effect of nonsurgical periodontal treatment on the severity of drug-induced gingival overgrowth in transplant patients. Quintessence Int. 2014:45:115-24.

35. Pilatti GL, Sampaio JE. The influence of chlorhexidine on the severity of cyclosporin A-induced gingival overgrowth. J Periodontol. 1997;68:900-4.

36. Mavrogiannis M, Ellis JS, Seymour RA, Thomason JM. The efficacy of three different surgical techniques in the management of drug-induced gingival overgrowth. J Clin Periodontol. 2006:33:677-82.

37. Hernandez G, Arriba L, Frias MC, de la Macorra JC, de Vicente JC, Jimenez C, et al. Conversion from cyclosporin a to tacrolimus as a non-surgical alternative to reduce gingival enlargement: a preliminary case series. Periodontol. 2003;74:1816-23.

38. James JA, Boomer S, Maxwell AP, Hull PS, Short CD, Campbell BA, et al. Reduction in gingival overgrowth associated with conversion from cyclosporin a to tacrolimus. J Clin Periodontol. 2000;27:144-8.

39. Mavrogiannis M, Ellis JS, Thomason JM, Seymour RA. The management of drug-induced gingival overgrowth. J Clin Periodontol. 2006:33:434-9.

40. Ross IF. Tooth movement and repositioning of the mandible without appliances. J Prosthet Dent. 1974:31:290-6.

41. Gaumet PE, Brunsvold MI, McMahan CA. Spontaneous repositioning of pathologically migrated teeth. J Periodontol. 1999:70:1177-84.

\section{Ready to submit your research? Choose BMC and benefit from:}

- fast, convenient online submission

- thorough peer review by experienced researchers in your field

- rapid publication on acceptance

- support for research data, including large and complex data types

- gold Open Access which fosters wider collaboration and increased citations

- maximum visibility for your research: over $100 \mathrm{M}$ website views per year

At $\mathrm{BMC}$, research is always in progress.

Learn more biomedcentral.com/submissions 